\title{
Research on the Technology Enterprise Performance Evaluation Index System
}

\section{Lan Fu}

Jiangxi University of Finance and Economics Statistics School.

Email: fulan60010068@sina.com

Received May, 2013

\begin{abstract}
The purpose of this essay is to design a framework of a performance evaluation system which is subject to the characteristics of China technology enterprises. It based on the analyzing the principles and significance of the performance evaluation system of technology enterprises. The framework will promote the standardize management of technology enterprises of China.
\end{abstract}

Keywords: The Technology Enterprise; Performance Evaluation; Index System

\section{Introduction}

\subsection{Recognized Principles and Basis of a Technology Enterprise}

There is no clear conclusion concerning the definition of the technology enterprise. However, people can obtain the identified principles and basis of a technology enterprise based on the operation of the relevant documents and the relevant departments of government.[1]

\subsubsection{The Recognized Principles of a Technology Enterprise}

The loose-principle, at present, the ministries and commissions of the State Council, the institution of financial regulatory and local council have a different standard on the recognized of a technology enterprise. For instance, the Technology Ministry, the Financial Ministry and the State Administration of Taxation issued "Recognition of management methods concerning the high-tech enterprise”. While the China Banking Regulatory Commission (CBRC) and the Technology Ministry jointly released guidance on further increase of SME credit support. Therefore, for the recognition of a technology enterprise, it should take the appropriate loose principles instead of narrow principles and cover all tech SMEs and microenterprises.

The low-cost principle, for the recognition of a technology enterprise, the identification of cost should be considered. In addition, it should try to reduce the recognition of cost. Thus, the requirements of a recognized standard should not be too complex, and the identified process should not be overly inconvenient. Briefly, the recognized standard should be as simple as possible, easy operation and implementation.

\subsubsection{The Recognized Bases of a Technological Enterprise}

In light of the loose and low-cost principles, a technology enterprise can be recognized if it can meet one of the following conditions:

A) A enterprise has been identified as high-tech enterprises;

B) A private technology enterprise has been registered in the Provincial Science and Technology Department;

C) A enterprise has implemented a municipal or munipal above technology project in the past three years;

D) A enterprise of implementing patent technique or independent proprietary intellectual rights.

\subsection{The Importance of Evaluation of a Technology Enterprise's Performance}

The essence of performance evaluation is a measure of management and control. It provides a reference to managers by the comparison of an occurred result and a pre-determined criterion before they take a further step. Firstly, correct performance evaluation for technology companies can assist investors to correctly understand the technology enterprises. Secondly, it makes the incentives function properly. Further more, management methods and process innovation of technology enterprises benefit from it.

However, enterprise production and management capabilities, process and results can be reflected through a number of financial indicators and innovation ability 
index. According to the characteristics of technological enterprise, its performance indicates the reality of the profitability and future growth and development potential. Therefore, constructing a comprehensive scientific evaluation index system has become an important part of the performance evaluation of the technological enterprises.

\subsection{The Characteristics of Technological Enterprises}

\subsubsection{Enterprises with a Flexible Organizational Structure}

The flexibility of its organizational structure is mainly reflected in two aspects. On the one hand, companies can adjust the setting of the business functions in terms of the changes of the market. On the other hand, employees can at any time according to the changes of the business internal flow. This flexibility allows the entire organization in a flexible flow state, able to change with the external market fluctuations.

\subsubsection{Enterprises have Employees with a Strongsense of Innovation and Innovative Capacity}

The employees in the enterprise are initiative and strong knowledge-based employees. They possess the knowledge and skills of the enterprise, the comprehensive judgment and decision-making ability, and are subject to full authorization and incentive to work can work independently.

\subsubsection{Speeding up the Product and Service Innovation of Enterprises.}

The face of the speed changes in the environment, the enterprise through continuous, comprehensive collaborative innovation to the market faster than the competition to provide products and services to meet customer needs, and thus gain an advantage in the market competition.

\subsubsection{Production by Standardized Transition to the Non-standardized}

Enterprises should pay more attention to the market demand for differentiated and the characteristics of individual consumers. In addition, enterprise can adopt a nonstandardized production according to customer demand. Meanwhile, it utilizes small quantity and variety of proction to replace the large quantities and single product of traditional enterprises. Finally, technology enterprises obtain business growth through emphasizing innovation.

\section{The principles of Constructing a Technology Enterprise Performance Evaluation system}

\subsection{The Principle of Objective and Impartial}

The inputs and outputs of the process of the high-tech enterprises are extremely complex and difficult to understand. This leads to the performance evaluation is very prone to subjective bias, which provides an opportunity to meet the different purposes of the evaluators. Therefore, in the evaluation of corporate performance, the evaluator must be judged aloof and independent stance and exquisite competent. In order to reduce the influence of artificial factors of enterprise performance evaluation, enterprise should evaluate pros and cons objective stance, a fair attitude evaluate gains and losses, reasonable way to measure corporate performance[2].

\subsection{Scientific and Rational Principles}

The design of an effective performance evaluation system must reflect the unique characteristics of the enterprise. Performance evaluation system can follow the traditional performance evaluation system in some of the indicators of technology enterprises, with its own characteristics, taking into account the scientific development of a number of other indicators. The relationship between the profit targets of enterprise and technology enterprises in the research and development process, innovation, knowdge assets contribution is vague and difficult to quantify. Consequently, scientific and reasonable method should be used to evaluate these aspects.

\subsection{Condensed Applicable Principles}

Traditional performance evaluation in the assessment of technological enterprise performance is too one-sided and simplistic. Thus, it is easy to distort the true performance of the high-tech enterprises. However, if in constructing technology enterprise performance evaluation system in the face mask to work out the many profound and sophisticated indicators, the evaluators will inevitably lead to a loss. So we must seize the technological characteristics of enterprises to identify the essential things to work out some key indicators operability. Otherwise, the performance evaluation system can not be members agree, accepted by the organization members. This situation will lead to organization members ignore its existence or less reluctant to comply with. Such information provided may be inaccurate, untimely and not objective. Therefore, a good performance evaluation system must be as required according to the user's heart design.

\subsection{The Principles of Service Goals}

The purpose of the business existence is to obtain the profit, which represents the efforts of enterprise on the profitability of the corporate research and development activities, production and business activities, marketing activities and other aspects. Enterprise performance evaluation should also serve the aims of enterprises and contribute to the profitability of enterprises. Enterprise 
Performance Evaluation can found some of the problems that hinder the profitability of the business by the evaluation of the key factors affecting the profitability of the business. Then it can provide timely and detailed information for managers operating decisions.

\section{Technology Enterprise Performance Evaluation index System}

\subsection{The Technology Enterprise Performance Evaluation of design}

From the above analysis, constructing a technology enterprise performance evaluation index system should not only consider the profitability of the enterprise but also to consider the growth and development potential of technology enterprise.[3] However, growth and development potential of an enterprise is depends primarily on the intellectual capital of the enterprise. Therefore, technology enterprise performance evaluation system should include two aspects. One is to reflect the profitability of the financial indicators. Another one is to reflect the innovation ability index of business growth and future development potential. This essay designed a technology enterprise performance evaluation index system. As shown.

\subsection{Interpretation of Indicators and Data Sources}

\subsubsection{Interpretation of Indicators}

ROE $=$ net profit $/$ average net capital $\times 100 \%$

Net profit margin $=$ net profit $/$ sales total income $\mathrm{x}$ $100 \%$

Return on total capital $=$ EBIT $/$ average total capital $\mathrm{x}$ $100 \%$

Total capital turnover $=$ Net operating income $/$ Average total assets $\times 100 \%$

Current capital turnover $=$ the main net operating income / Average total current assets $\times 100 \%$

Capital-liability ratio $=$ Total liabilities $/$ total assets $\mathrm{x}$ $100 \%$

Multiples of interest earned $=$ EBIT $/$ interest expense

The growth rate of net profit $=$ (base period sales sales of the reporting period) / sales of the reporting period

The growth rate of net capital $=$ (base period net assets - net assets of the reporting period) / net assets of the reporting period $\times 100 \%$

The growth rate of total capital $=$ (base period total assets - total assets of the reporting period) / reporting period, the total assets $\times 100 \%$

Per capita training costs $=$ annual training costs $/$ sales revenue $\times 100 \%$

Introduction of talent invested $=$ annual talent refer- ence funds / sales revenue $\times 100 \%$

Quality of human capital $=$ with college or higher staff / number of employees $\times 100 \%$

Technical inputs $=\mathrm{R} \& \mathrm{D}$ expenses $/$ total sales $\times$ $100 \%$

Intellectual Property right $=$ the number of corporate patent owners

Innovation capability $=$ new product to market $/$ the total number of products developed x 100\%

Marketing investment $=$ sales investment $/$ sales revenue $\times 100 \%$

Social relations $=$ bank corporate credit rating (good, general, poor)

Market share $=$ dominant product sales revenue $/$ the same industry product revenue $\times 100 \%$

New product revenue to total revenue ratio $=$ new product revenue / total revenue $\times 100 \%$

New product profit to total profit ratio $=$ profit $/$ total profits $\times 100 \%$

\subsubsection{Sample Selection and Data Collection Methods Recommended}

The paper selected the range of samples form the province science and technology enterprises. The sample data is from a table statistics of the Provincial Bureau of Statistics, industrial enterprises, financial statements, and annual report data. This involves multiple industries, the pharmaceutical industry, mechanical industry, electronics and communications industry, with full representation.

\section{Technology Enterprise Performance Evaluation Method Selection}

In order to reflect the performance of technology entersprises' effectively, enterprises could choose a method which can quantify the impact factors of performance. This is the purpose of selection of performance evaluation method. The method is not based on objective methods of expert judgment. Thus, it can remove the interference of artificial factors, and demonstrate the objectivity and fairness. In addition, technology enterprises with high input, complex performance evaluation, covering a wide range of indicators reflect different aspects enterprise performance situation, but in a way larger principal component analysis can simplify complex problems, an effective solution to this problem. Moreover, from the sample size, the method can ensure that the number of samples is far more than the number of indicators, which meet the basic requirements of the principal component analysis. Finally, principal component analysis is in line with the characteristics and the development of technology enterprises influencing factors to adapt its complex characteristics.

Principal component analysis is a method for dealing 
with multi-information. The principle of the method is to refine a few unrelated composite indicators from the multiple interrelated indicators. In other words, it extracts important information from the original wealth of information. Then it composes a new composite indicator. Meanwhile, these indicators can fully express the originnal information to simplify the evaluation index purposes on the basis of loss or less loss.

Principal component analysis is based on the data itself and is an objective evaluation of the weighting method. It is in terms of the embodied values on the evaluation indicators of the actual observations, and analysis of the internal structure of the relationship between the various indicators, accurate exclude irrelevant indicators, so as to ensure the objectivity of the evaluation results based on maximizing the process simple, fair, objective evaluation of the performance. Different stakeholders have a great difference in attention for each indicator. However, the principal component analysis can simplify information properly. Therefore, this method is a good way to coordinate the above problems.

In summary, this essay indicates the unique character- istics of technology enterprises and adopts the principal component analysis to assess the performance of the technology enterprises. It also combined the financial indicators and innovation indicators through analyzing a few new variables which transforms from the original number of variables. However, it still remains the basically information of the original variables. According to the data it to get the weighting of indicators in a comprehensive performance evaluation obtained evaluation results more objective and fair.

\section{REFERENCES}

[1] X. C. Meng, "Growth of Venture Capital and High-tech Enterprises,” Southwestern University of Finance and Economics Press, 2003

[2] F. Micro, "Intellectual Capital Evaluation Index System of Industrial Engineering and Management,” Vol.1, 2001.

[3] "Orchestration High-tech Enterprises, Market-oriented Strategy and Strategic Performance Evaluation Study,” Scientific management research Study, Vol. 6, 2005. 